\title{
Improving on Network Congestion
}

\author{
N.Sivaranjani, Amudha S, Mary Linda I
}

\begin{abstract}
A Denial of Service (DoS) assault is a malignant endeavor to keep prescribed end-clients of a web website or net supplier from getting to it, or diminishing their capacity to accomplish this. A Distributed Denial of Service (DDoS) assault is a sort of DoS trap wherein various PC structures are used to incapacitate the host center point or web site. Imperfections both in customers' use of a framework or in the specific of shows has completed in gaps that permit various sorts of system ambush. This assessment saw on flooding ambushes and grouping such assaults as either over the top value flood or low-charge flood. At long last, the ambushes are assessed contrary to statute identified with their working conduct, operational trademark and procedure. This paper examines a factual system to break down the circulation of network guests to perceive the customary system traffic lead. The EM calculation is reviewed to inexact the dispersion parameter of Gaussian blend. Some other time gathering examination strategy is figured it out. This paper furthermore contemplates a method to capture inconsistencies in system guests, in view of a non-bound $\alpha$-strong first-request model and factual theory giving it a shot.
\end{abstract}

Keywords: - DDoS Impact, Anomaly Detection Method, a-Stable Model

\section{INTRODUCTION}

Appropriated refusal of-supplier assaults (DDoS) represent a sizeable danger to the Internet, and subsequently insurance systems had been proposed to battle them. avoid those security structures, and researchers along these lines adjust their strategies to address new ambushes. The DDoS subject is growing brisk, and it is transforming into an extending hard to understand a general point of view on the task.

This paper attempts to introduce the DDoS subject through growing a logical classification of DDoS ambushes and DDoS confirmation structures. The purpose of the paper is to focus on the noteworthy features of each attack and security methods and give mindfulness that may cause a predominant data of the DDoS issue[1].

A Denial of Service assault is an attempt with the guide of somebody or a gathering of people to injure a web administration. This could have serious impacts, specifically for offices like Amazon and flipkart which rely upon their on line accessibility to do endeavor between systems

Revised Manuscript Received on December 11, 2019

N.Sivaranjani, Department of Computer science and Engineering, Bharath Institute of Higher Education and Research, Chennai, Tamilnadu, India. Email: ranjibalas@gmail.com

Amudha S, Department of Computer science and Engineering, Bharath Institute of Higher Education and Research, Chennai, Tamilnadu, India. Email: amudha17s@gmail.com

Mary Linda I, Department of Computer science and Engineering, Bharath Institute of Higher Education and Research, Chennai, Tamilnadu, India. Email: catchlin.18@gmail.com Aggressors always change their mechanical assembly to

administration. In the not all that inaccessible past there had been some huge scale assaults focusing on prominent net sites. Thus, there are directly a great deal of endeavors being made to give components to hit upon and alleviate such hacking. Despite the fact that the essential disavowal of transporter ambushes did never again take quite a while prior (apparatuses that robotize setting up of an assault network and propelling of assaults, began acting in 1998), there are a huge number of refusal of bearer attacks which have been watched. The assaults might be of 3 administrative work. A) Attacks abusing vulnerabilites or in bugs. B) Attacks that exhaust all of to be had sources at the objective gadget. C) Attacks that eat up all the system traffic accessible to the sufferer gadget. The third sort of ambushes is known as data transmission assaults. A dispensed stage will end up being especially appealing for such ambushes as some proportion of convictions facilitated from various hosts that can create an extraordinary traffic at and near the objective gadget, halting the majority of the courses. Assurance towards such tremendous scale designated data transfer capacity ambushes is one of the greatest troublesome (and pressing) issue to manage in these day's net. CERT surveys data transfer capacity attacks as an expanding number of being the most ordinary state of Denial of Service ambushes.

\section{DDOS ATTACK OVERVIEW}

The working structures and system conventions are created without issue security designing which results in giving assailants an assortment of defenseless machines. These unreliable and unrivaled machines are utilized by DDoS aggressors as their military to discharge ambush. An aggressor normally send consecutive attack projects to the shaky machines. Contingent on unpredictability in rationale of fixed bundles those compromised machines [5] are known as Zombies and are as one called bots and the assault network is known as a botnet. Programmers control guidelines to zombies, which thusly flip impart it to zombies for propelling assault.

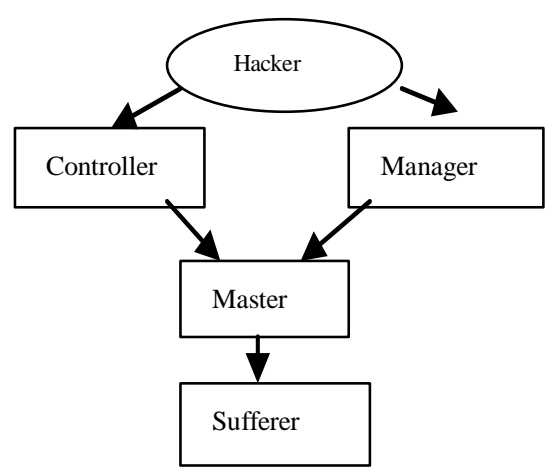

Fig 1. Attack module 
DDOS assaults are characterized into two classifications: flooding assaults and Flash Crowd assaults. Flooding DDoS attacks substantial resources which incorporate system assignment/load by means of stacking of hyperlink with huge amount of bundles. Blaze Crowd ambushes utilize the anticipated direct of conventions alongside TCP and HTTP to the assailant's favorable position. The benefits of the server are tied up through apparently genuine solicitations of the aggressors, and as a result check the server from exchanges or demands from approved clients.

\section{DDOS COLLISION}

Appropriated Denial-of-organization (DoS) assaults were in the domain of for a long time. In the PC social order field, DDoS attacks typically take totally one of two regulatory work [4]: (an) abusing the framework clients or server programs, attempting to crash the utility (and in all likelihood the host on which it is working) or (b) Flooding a framework server with phony visitors, making it unimaginable for the server to get hold of the structure considerable site visitors. The past are commonly assisted through using 'pad attack ambushes' wherein a framework writing computer programs is sent a significant measure of facts which it fails to oversee prohibitively, on the other hand overwriting noteworthy convictions with Bigdata.

Guarding towards DoS assaults fuses using calm working structures involving UNIX which over route protection (to vanquish an application crash in the whole machine), holding invigorated with security patches and frail pointers (to stop successive projects which can be susceptable to cushion invaded assaults) and following and controlling network system burden (to address flooding ambushes). DDoS ambushes are a pristine variation on this old fashioned issue. A DDoS assault utilizes net-works of art flooding, yet is progressively hard to shield towards the assault is discharged from burdens or possibly a huge number of hosts all the while. Instead of going about as an extra of site guests originating from an unmanaged have, a DDoS assault appears in its region as normal site guests originating from a huge scope of hosts. This makes it harder to find and control [3]. At the point when there are such a great deal of hosts embroiled, the strategic issues of hindering the ambush and comprehend its genuine advancement are noteworthy The Internet turned out to be genuinely detached with the defenselessness issues, and a genuine arrangement would include re-designing the total part engineering. Along these lines it's made essential to take pre-emptive occasions to diminish the plausibility of these attacks and lessening throughput wastefulness.

\section{INTERNET ARCHITECTURE}

The Internet wound up conscious with secluded item parts, not security, in plan, and it changed into obviously an accomplishment in arriving at this aim. It gives its friend quick, simple and sensibly evaluated message trade components, noteworthy with different higher-degree conventions that ensure trustworthy or opportune dispatching of messages or a positive level of fine of administration. Web design pursues the quit-to-stop worldview: trades quit has establishment confused functionalities to acquire wanted supplier arrangement, even as the center level presents abare least, best-exertion transporter. The Internet is controlled in a genuine customer server topology; subsequently no strategy can be implemented among its individuals. Such structure opens various wellbeing issues that offer potential outcomes in dispersed refusal of-administration attacks:

Web insurance is exceptionally simultaneously supporting. DDoS assaults are typically discharged from frameworks that are debilitated through security related linkages. Regardless of how pleasantly covered the end hub machine may also be, its powerlessness to DDoS assaults depends upon at the condition of security.

Web resources are compelled. Every Internet empowered PC has obliged assets that can be misused through a gamut variety of clients.

Aggregate intensity of many is significantly more prominent than intensity of few. Circulated coordination and simultaneous noxious moves by method for certain hubs can continually be antagonistic to other people, if the assets of the assailants are enormous than the wellsprings of the end client PC hubs.

Knowledge and assets aren't gathered: At the equivalent time, a huge system data transfer capacity prompted the plan of inordinate transmission capacity system courses in the network. Consequently, pernicious customers can abuse the accessibility of assets network for conveyance of a few messages to a hacked hub. Trouble in following restored the assault to the stock Most (if no longer the majority) of the web keeps running on the TCP/IP convention. The hidden convention (IP) is to a great extent connectionless in condition. At each transitional advance from the source to the goal detect, the decision about the following host to ahead the parcel is finished. All such steering choices are made based on the bargained spot managed. It is in this manner conceivable to reroute parcels with wrong supply IP addresses and employ them to release Denial of Service attacks. This approach is known as IP spoofing. Users with sufficient rights on a internet node do have the potential to make such duplicate packets.

The framework components or segments of the interconnected hubs and between systems is, for example, of accessible sources. Data transfer capacity devouring force and capacity limits is all goals of Denial of Service ambushes. In the event that these assets are developed by methods for gigantic execution plans, it raises the circumstance proclivity at the level of an attack ought to accomplish make progress.

\section{RESULTS}

In insights based essential technique incorporates a typical network conduct and all guests that go amiss from the ordinary is significant as errant qualities. This strategy is utilized to examine network guest's model on a current network. By investigating system site guests and preprocessing the records with entangled factual calculations, the frameworks perform design acknowledgment in the realized normal network guest's logs. 
All bundles are given an abnormality rating and if the vagueness score is superior to a definite edge, the interruption discovery gadget will create a caution.

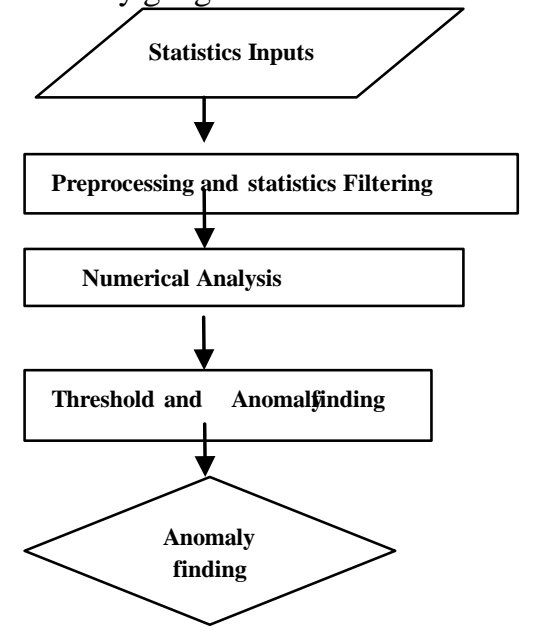

Fig. 2 Statistical Approach for Network Anomaly finding

This technique has various points of interest. It can identify new ambushes like forswearing of administrations assaults, trojan pony or infection. It is moreover ready to detect low profundity moderate pace assaults. Another essential bit of leeway is that it is presumably less entangled to keep up than a standard basically based strategy because of the reality we would prefer not to maintain and supplant any report of confirmation [5]. The crucial issue with this sort of technique is the social event of reasonable limit cost. Issue of false positive and false negative ascent up because of this worth. On the off chance that worth is put low than proportion of false awesome blast whenever cost is set to high, at that point the atypical games can't be affirm way copied phony terrible transfer to.

\section{a) Gaussian Mixture Model:}

Look at the inventory data, the network traffic may not be clarified as a Gaussian sharing. The sharing of a Gaussian appears as circle and its lingering must be ordinary. The Gaussian blend adaptation likelihood thickness capacity is a weighted capacity of a few Gaussian structures. Here it's far taken the Gaussian mix situation with three single Gaussian dissemination shapes for instance. $\mathrm{Q}(\mathrm{x})=\alpha 1 \mathrm{~g}(\mathrm{x} ; \mu 1, \theta 1)+\alpha 2$ $\mathrm{k}(\mathrm{x} ; \mu 2, \theta 2)+\alpha 3 \mathrm{~g}(\mathrm{x} ; \mu 3, \theta 3)$

The representative rundown $(\alpha 1, \alpha 2, \alpha 3)$ need to validatethe resulting condition: $\alpha 1+\alpha 2+\alpha 3=1$

The univariate Gaussian blend circulation is set as:

$\mathrm{q}(\mathrm{x} ; \mu, \sigma 2)=(2 \pi)-\mathrm{d} / 2 \sigma-\mathrm{d} \exp [-((\mathrm{x}-\mu) \mathrm{T}(\mathrm{x}-\mu)) / 2 \sigma 2]$

The bigger Gaussian models, the more noteworthy authentic the Gaussian dissemination blend model may be. In the strategy directly here it coordinates the amount of Gaussian conveyance ordinary will ensure the fleeting timespan worth and execution.

\section{b) 5.2 EM Algorithm}

$\mathrm{EM}$ is an iterative method for the expense of a couple of scanty sum, gave the estimations of some associated, analyzed sum. The system is to initially perceive that the sum

is instead of as an incentive in a couple parameterized likelihood strategy. The EM system is talked about:

Arrangement the sharing imperative and rehash until the association condition is fulfilled:

$\mathrm{N}$-Step: foreseen the anticipated estimation of the obscure factors, given the present dayh $=\mathrm{N}[\ln (\mathrm{V}$ to augment the closeness of the statisticsh)].

Here, the EM algorism is utilized to foresee the normal expense of different Gaussian sharing which reaches out with each unique, to take up the type of a Gaussian blend sharing. The methodology is the blend of Gaussian model is estimated to fit the system site guests check.

\section{CONCLUSION}

This paper has provided idea around the DDoS Attacks and their issues on between system site guests. Here paper contemplated a DDoS assault to comprehend the conveyance of network guests to comprehend the typical network site guest's conduct. This exploration article has likewise talked about flooding assaults. The EM calculation is utilized to estimated the ordinary circulation parameter of Gaussian total conveyance variant and other differing structures. Some other time gathering assessment method is examined. This paper additionally referenced a method to comprehend oddities in network load-adjusting, controlled by a non-obliged astable form and measurable hypothesis looking at.

\section{REFERENCES}

1. Kumaravel A., Meetei O.N.,An application of non-uniform cellular automata for efficient cryptography,2013 IEEE Conference on Information and Communication Technologies, ICT 2013,V-,I-,PP-1200-1205,Y-2013

2. Kumarave A., Rangarajan K.,Routing alogrithm over semi-regular tessellations,2013 IEEE Conference on Information and Communication Technologies, ICT 2013,V-,I-,PP-1180-1184,Y-2013

3. Dutta P., Kumaravel A.,A novel approach to trust based identification of leaders in social networks,Indian Journal of Science and Technology,V-9,I-10,PP--,Y-2016

4. Kumaravel A., Dutta P.,Application of Pca for context selection for collaborative filtering,Middle - East Journal of Scientific Research,V-20,I-1,PP-88-93,Y-2014

5. Kumaravel A., Rangarajan K.,Constructing an automaton for exploring dynamic labyrinths,2012 International Conference on Radar, Communication and Computing, ICRCC 2012,V-,I-,PP-161-165,Y-2012

6. Kumaravel A.,Comparison of two multi-classification approaches for detecting network attacks, World Applied Sciences Journal,V-27,I-11,PP-1461-1465,Y-2013

7. Tariq J., Kumaravel A.,Construction of cellular automata over hexagonal and triangular tessellations for path planning of multi-robots,2016 IEEE International Conference on Computational Intelligence and Computing Research, ICCIC 2016,V-,I-,PP--,Y-2017

8. Sudha M., Kumaravel A.,Analysis and measurement of wave guides using poisson method,Indonesian Journal of Electrical Engineering and Computer Science,V-8,I-2,PP-546-548,Y-2017

9. Ayyappan G., Nalini C., Kumaravel A.,Various approaches of knowledge transfer in academic social network,International Journal of Engineering and Technology,V-,I-,PP-2791-2794,Y-2017

10. Kaliyamurthie, K.P., Sivaraman, K., Ramesh, S. Imposing patient data privacy in wireless medical sensor networks through homomorphic cryptosystems 2016, Journal of Chemical and Pharmaceutical Sciences 


\section{Improving on Network Congestion}

11. Kaliyamurthie, K.P., Balasubramanian, P.C. An approach to multi secure to historical malformed documents using integer ripple transfiguration 2016 Journal of Chemical and Pharmaceutical Sciences 9

12. A.Sangeetha,C.Nalini,"Semantic Ranking based on keywords extractions in the web", International Journal of Engineering \& Technology, 7 (2.6) (2018) 290-292

13. S.V.GayathiriDevi,C.Nalini,N.Kumar,"An efficient software verification using multi-layered software verification tool "International Journal of Engineering \& Technology, 7(2.21)2018 454-457

14. C.Nalini,ShwtambariKharabe,"A Comparative Study On Different Techniques Used For Finger - Vein Authentication", Internationa Journal Of Pure And Applied Mathematics, Volume 116 No. 8 2017, 327-333, Issn: 1314-3395

15. M.S. Vivekanandan and Dr. C. Rajabhushanam, "Enabling Privacy Protection and Content Assurance in Geo-Social Networks", International Journal of Innovative Research in Management, Engineering and Technology, Vol 3, Issue 4, pp. 49-55, April 2018.

16. Dr. C. Rajabhushanam, V. Karthik, and G. Vivek, "Elasticity in Cloud Computing", International Journal of Innovative Research in Management, Engineering and Technology, Vol 3, Issue 4, pp. 104-111, April 2018.

17. K. Rangaswamy and Dr. C. Rajabhushanamc, "CCN-Based Congestion Control Mechanism In Dynamic Networks", International Journal of Innovative Research in Management, Engineering and Technology, Vol 3, Issue 4, pp. 117-119, April 2018.

18. Kavitha, R., Nedunchelian, R., "Domain-specific Search engine optimization using healthcare ontology and a neural network backpropagation approach", 2017, Research Journal of Biotechnology, Special Issue 2:157-166

19. Kavitha, G., Kavitha, R., "An analysis to improve throughput of high-power hubs in mobile ad hoc network" , 2016, Journal of Chemical and Pharmaceutical Sciences, Vol-9, Issue-2: 361-363

20. Kavitha, G., Kavitha, R., "Dipping interference to supplement throughput in MANET" , 2016, Journal of Chemical and Pharmaceutical Sciences, Vol-9, Issue-2: 357-360

21. Michael, G., Chandrasekar, A.,'Leader election based malicious detection and response system in MANET using mechanism design approach", Journal of Chemical and Pharmaceutical Sciences(JCPS) Volume 9 Issue 2, April - June 2016.

22. Michael, G., Chandrasekar, A.,'Modeling of detection of camouflaging worm using epidemic dynamic model and power spectral density", Journal of Chemical and Pharmaceutical Sciences(JCPS) Volume 9 Issue 2, April - June 2016.

23. Pothumani, S., Sriram, M., Sridhar, J., Arul Selvan, G., Secure mobile agents communication on intranet,Journal of Chemical and Pharmaceutical Sciences, volume 9, Issue 3, Pg No S32-S35, 2016

24. Pothumani, S., Sriram, M., Sridhar, Various schemes for database encryption-a survey, Journal of Chemical and Pharmaceutical Sciences, volume 9, Issue 3, Pg NoS103-S106, 2016

25. Pothumani, S., Sriram, M., Sridhar, A novel economic framework for cloud and grid computing, Journal of Chemical and Pharmaceutical Sciences, volume 9, Issue 3, Pg No S29-S31, 2016

26. Priya, N., Sridhar, J., Sriram, M. "Ecommerce Transaction Security Challenges and Prevention Methods- New Approach” 2016 ,Journal of Chemical and Pharmaceutical Sciences, JCPS Volume 9 Issue 3.page no:S66-S68 .

27. Priya, N.,Sridhar,J.,Sriram, M."Vehicular cloud computing security issues and solutions" Journal of Chemical and Pharmaceutical Sciences(JCPS) Volume 9 Issue 2, April - June 2016

28. Priya, N., Sridhar, J., Sriram, M. "Mobile large data storage security in cloud computing environment-a new approach" JCPS Volume 9 Issue 2. April - June 2016

29. Anuradha.C, Khanna.V, "Improving network performance and security in WSN using decentralized hypothesis testing "Journal of Chemical and Pharmaceutical Sciences(JCPS) Volume 9 Issue 2, April - June 2016.

\section{AUTHORS PROFILE}

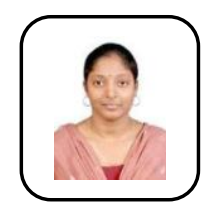

N.Sivaranjani Assistant Professor, Department of Computer science and Engineering, Bharath Institute of Higher Education and Research, Chennai, India

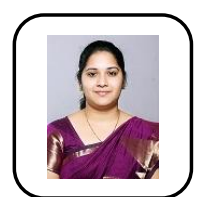

Amudha S Assistant Professor, Department of Computer science and Engineering, Bharath Institute of Higher Education and Research, Chennai, India

Mary Linda I Assistant Professor, Department of Computer science and Engineering, Bharath Institute of Higher Education and Research, Chennai, India 